\title{
An Extended Model for the prediction of Strength Enhancement in Laterally reinforced Concrete Columns
}

\author{
T. M. Pallewatta
}

\begin{abstract}
:
A behaviour-oriented model is enhanced for the confinement effectiveness and strength enhancement of concrete under axial compression, subject to passive confinement by lateral reinforcement. The basic Model developed on rationalizing the behaviour of confined concrete on the basis of three dimensional concrete constitutive law based FEM simulation results and idealized experimental results on laterally confined concrete cores was extended on the lines of confinement uniformity afforded by complex lateral reinforcement arrangements and the confinement contribution of longitudinal reinforcement. Confinement efficiency of lateral reinforcement layouts were quantified through confinement effectiveness index, which is the ratio of induced spatial average confining stress to the maximum potential confinement capacity of lateral reinforcement arrangement. This index is represented by lateral reinforcement detailing as well as material parameters in the Extended Model as well. Conceptual 'lowest confined section' was adopted to formulate the strength enhancement due to confinement, under average confining stress and double effect of uniformity of lateral confinement layout.
\end{abstract}

Keywords: $\quad$ Extended Model, lateral confinement, concrete compressive strength

\section{Introduction}

Many brittle materials exhibit enhancement in strength as well as in ductility, when subjected to axial compression under the influence of active lateral confinement. This is also true for concrete which is one of the most versatile construction materials, which also happens to be brittle. However, realizing enhancement of above stated mechanical properties in brittle materials, including concrete, under the influence of passive lateral confinement had been rigorously debated until the latter part of the past century.

For better pre-failure strength and post-failure safety, any possible enhancement of strength coupled with increased capacity for deformation or ductility is a significant advantage for concrete. However, for this purpose, utilization of active confinement is impractical due to practical limitations and cost involved in lateral pre-stressing. On the positive side, analytical and experimental research conducted during the past few of decades have amply indicated that passive lateral confinement could significantly contribute in the enhancement of strength and ductility in concrete.

Lateral confinement can generally be provided to a concrete core by steel reinforcement in the form of casings or discretely placed ties and hoops. Since confinement of concrete by laterally placed reinforcement inherently can only provide passive confinement, which is generated only when concrete laterally expands against the reinforcement this provides a remarkably simple and cost effective way of supplementing mechanical properties of reinforced concrete. For structures, especially located in seismic zones, this enhanced capacity would provide safety and serviceability under seismic overloading.

A behaviour oriented model for predicting strength enhancement in concrete cores under simple discreet lateral confinement was presented in a previous paper [14]. This model was developed, based on results of comprehensively conducted experimental studies verified by FEM based analysis employing a numerical model for concrete known as "Elasto-Plastic-Fracture model" [3, 4, $5,6]$, based on mathematically quantified four experimental facts namely; Fracture in hydrostatic stress state, Fracture in shear, Plasticity in shear and Plasticity in volume [9]. Confining steel was modelled under two idealizations where, one took only the hoop confinement effect based on only axial stiffness of steel, while the other accounted for the flexural and shear stiffness as well.

Eng. (Dr.) T. M. Pallewatta, Int. P Eng., C. Eng., FIE(Sri Lanka), MIAE(Sri Lanka), B.Sc. Eng. (Hons) (Moratuwa), M.Eng. (AIT), Dr. Eng. (Tokyo), Senior Lecturer in

Engineering, Department of Civil Engineering, The Open University of Sri Lanka. 
The behaviour oriented model had been verified [14] against experimental results by other researchers on discretely confined concrete columns under axial compressive loading $[1,2$, 7, 11, 12].

It is the aim of this paper to extend application range of the "behaviour oriented model" which was based on micro-mechanical FEM analysis results on trends and sensitivity of governing parameters combined with experimental results. Final outcome would be an "extended behaviour oriented model" for predicting the confinement effectiveness and strength capacity of laterally confined concrete cores for reinforcement configurations generally used in practice.

\section{2. "Behaviour Oriented Model" for Strength Enhancement [14]}

Concept of Confinement Effectiveness Index $(\alpha)$ which is defined as the ratio of spatial average confining stress developed at the peak strength of the core $\left(\sigma_{\mathrm{v}}\right)$ to the potential confinement capacity $\left(1 / 2 p f_{y}\right)$ [8] is the fundamental basis for this model. Following are the identified most influential parameters on the said confinement effectiveness.

1. The lateral reinforcement fraction, which is the volume ratio of lateral steel to that of the confined concrete core.

2. The lateral reinforcement spacing ratio (s/d), which is the ratio of lateral tie spacing and the least lateral dimension of the core.

3. The contribution of the flexural stiffness of lateral reinforcement arms.

The basic mathematical form of the confinement effectiveness index was given as in Eq. 2.1.

$$
\alpha=\frac{1}{1+K^{*}+K_{0}(s / d)^{\gamma}}
$$

Where, the factor $K^{*}$ (Eq. 2.2) termed the "Limit Uniformity Factor" represents the condition when spacing becomes zero (confined by a casing).

$$
K^{*}=\frac{0.7\left[\frac{p f_{y}}{f_{c o}}\right]^{2}}{F_{r}}
$$

In other words, $K^{*}$ indicates the limit case where confinement along the axis of the concrete core is uniform.

The parameter $K_{0}$ (Eq. 2.3) termed the "Uniformity Factor" accounts for the uniformity of confining stresses in the lateral direction when the spacing of lateral reinforcement becomes larger than zero.

$$
K_{0}=\frac{7}{F_{r}}
$$

In both above equations, $F_{r}$ is depicted by Eq. 2.4 , where it is a function of geometric properties of lateral reinforcement.

$$
F_{r}=\left[1+350\left[\left(\frac{\varphi}{L}\right)^{2}\right]_{e q}\right]
$$

The effects of the three influential parameters discussed above are illustrated in Fig. 2.1, which clearly indicate the contributions of different derived factors on the confinement effectiveness.

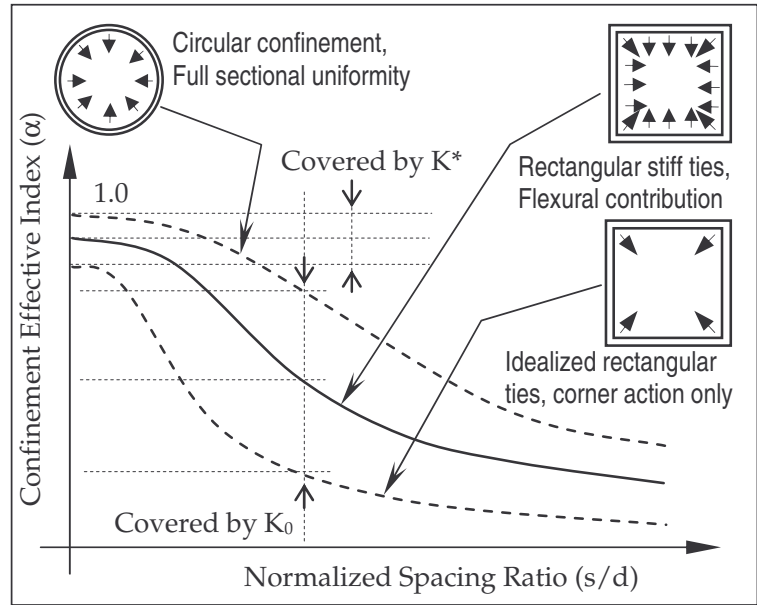

Fig. 2.1 - Range of the model for confinement effectiveness (illustrated)

The lateral confining stress distribution is conceptually illustrated Fig. 2.2.

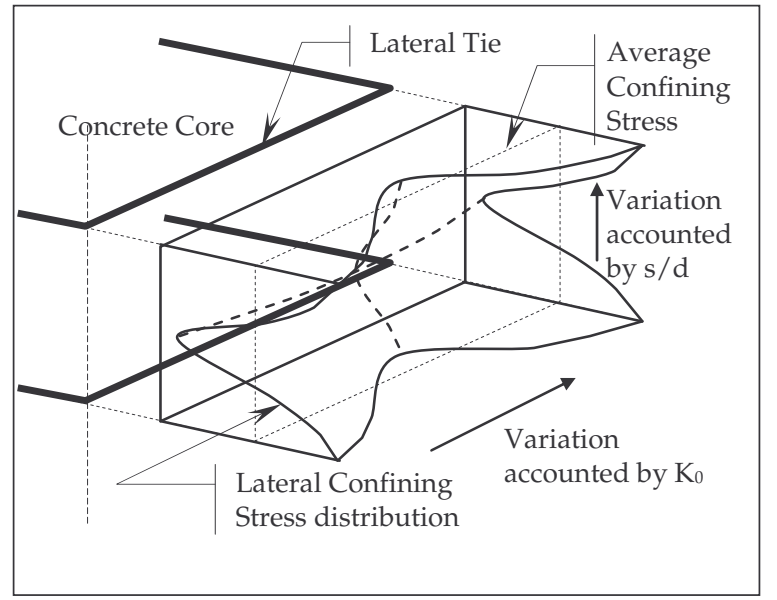

Fig 2.2 - Confining stress distribution by discretely spaced ties

Based on the concept of Confinement Effectiveness Index, volumetric average 
confinement stress on a concrete core under passive confinement could be found as given in Eq. 2.5.

$$
\sigma_{v}=\alpha \frac{1}{2} p f_{y}
$$

This average confinement stress is related to a conceptual minimum confining stress, which should be governing the peak strength of the confined concrete core. After accounting for non uniformity of confining stresses in both transverse and longitudinal directions of the concrete core, Eq. 2.6 had been proposed to represent the strength gain over an unconfined concrete core.

$$
\Delta f_{c}=6\left[\frac{\sigma_{v}}{1+0.6 K_{0} \sqrt{\left(s^{\prime} / d\right)}}\right]^{\frac{3}{4}}
$$

Thus, if the unconfined strength of a concrete core is given by $\mathrm{f}_{\mathrm{co}}$, then the peak strength of this core under confinement $f_{c c}$, shall be as given in Eq. 2.7.

$$
f_{c c}=f_{c o}+\Delta f_{c}
$$

As presented in the paper [14], this relationship had been only validated for simple square or circular hoops of lateral reinforcement confining a concrete core.

\section{Extension of the Behaviour Oriented Model}

The model concisely described in section 2 was developed under the idealized conditions with the aim of predicting the confinement mechanism in actual conditions. Ideal conditions used were simply a tool to identify the key parameters and their relationships in the confinement mechanism without the influence from other actions such as slipping at anchorage, behaviour of cover concrete etc. Generally, these actual factors are in difficult to be accounted for in an analytical procedure. Even if these factors are successfully idealized in computation, complexity imparted to analytical procedure will be high. On the other hand, using the Behaviour Oriented Model approach, overall influence of micro-mechanically complex conditions can be accounted. For this purpose, rational modification factors can be introduced to the basic model to make it applicable for axially symmetrical general confined concrete columns under axial compressive loading.
It is identified that the presence of longitudinal reinforcement supplements the action of lateral confinement in concrete. The longitudinal reinforcement is capable of transferring the lateral forces parted by expanding concrete, to the lateral reinforcement resulting in development of higher confining stresses and better lateral confinement stress uniformity. This contribution is dependent on the stiffness of lateral reinforcement and the physical distribution around the periphery of the confined core. In lateral reinforcement arrangements with intermediate ties, the contribution of the flexural stiffness of tie arms is accounted by the weighted average flexure/shape factor given in Eq. 2.4. Therefore, the effect to be accounted is the contribution of the longitudinal reinforcement to the uniformity of lateral stress distribution.

To account for the better confinement stress development and lateral stress distribution in the case of columns with longitudinal reinforcement, a simple modification for uniformity factor is proposed based on the peripheral spacing ratio of the longitudinal reinforcement and the amount of longitudinal reinforcement. The amount of longitudinal reinforcement is proposed in terms of ratio of longitudinal steel area to the area of core concrete $(\rho)$. The relation is presented in Eq. 3.1

$$
C^{*}=\frac{1}{2}\left(\frac{1+a / t}{1+10 \rho}\right)
$$

Here, $a$ is the space between two longitudinal bars on the periphery of core and $t$ is the core dimension of same side. In the case of a square section $t$ becomes $d$, the core size while for a circular section, $t$ becomes the diameter (D) of the core. This is more clearly illustrated in Fig. 3.1.

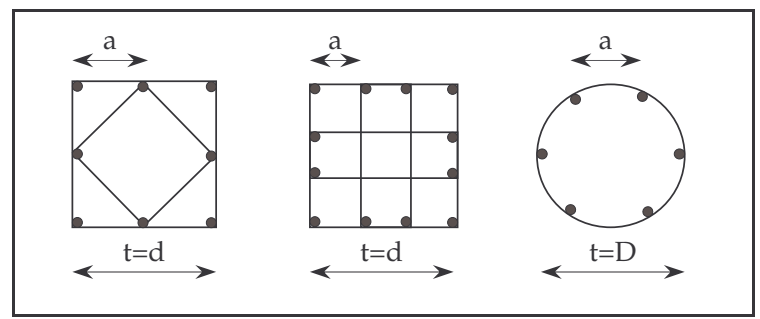

Fig. 3.1 Parameters for modification factor $\mathrm{C}^{*}$

The form for uniformity factor with the incorporation of the above stated modification factor is presented in Eq. 3.2. It should be noted that with higher stress uniformity, the numerical value of the $C^{*}$ becomes lower. The highest 
value for $C^{*}$ is unity (square column with square ties and no longitudinal reinforcement), while the lowest value depends on the longitudinal reinforcement ratio and peripheral spacing.

$$
K_{0}=\frac{7 C^{*}}{F_{r}}
$$

The Model was developed based on quasi-static loading of concrete in compression. In the case of higher strain rates applied in seismic loading conditions, based on the general understanding of concrete, it is construed that an increase in axial strength will result in concrete. The effect of loading rate on the confinement effectiveness was not investigated in the experimental study by the author. However, this effect on the strength of concrete, confined as well as unconfined had been the interest of some previous studies [2, 3, 4, 15]. By investigation of the parameters involved in these studies, and the results of compressive strength tests under varying strain rates, it was assumed that the ratio of peak strength at a higher loading rate (> $16 \mu$ strain/sec) to that under quasi-static strain rate $(<16 \mu$ strain/sec), is same for confined as well as unconfined concrete. Therefore, experimental results by Dilger et al. [2] and Watstien [15], on plain concrete specimens under higher strain rates were used to develop the relation for accounting higher strain rates than

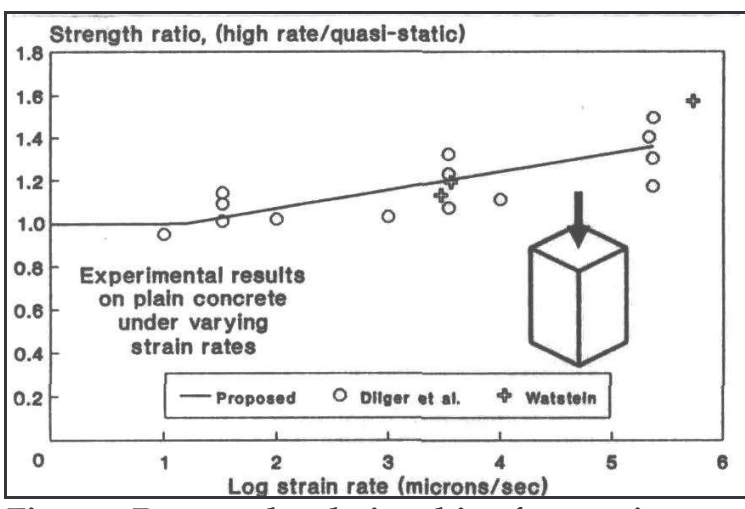

Fig. 3.2 Proposed relationship for strain rate effect

quasi-static. The proposed relation in Eq. 3.3 is compared with experimental data in fig. 3.2.

This relation is similar in form, to that proposed by Dilger et al [2]. Strain rates lower than $16 \mu$ strain/sec until $1 \mu$ strain/sec, are considered as quasi-static where the strength is assumed to be unaffected by the strain rate. In the relation $f_{\mathrm{cc}}$ is taken as the peak strength of confined concrete under quasi-static loading as predicted by the Model.

$$
\begin{gathered}
{\left[f_{c c}\right]_{\widetilde{\varepsilon}}=f_{c c}(0.9+0.085 \log \widetilde{\varepsilon}) . . \widetilde{\varepsilon} \geq 16 \mu / \mathrm{s}} \\
{\left[f_{c c}\right]_{\widetilde{\varepsilon}}=f_{c c} . .16>\widetilde{\varepsilon}>1 \mu / \mathrm{s} .3 .3}
\end{gathered}
$$

Since unconfined strength as well as confined strength are increased by higher strain rates, same relation as proposed by Eq. 3.3 is assumed for unconfined strength and the strength gain due to confinement under higher strain rates.

\subsection{Application to Square Sections with Longitudinal Reinforcement}

Simplest form of a square section with longitudinal reinforcement is four corner bars with a simple square tie. Such tests have been conducted by King [5] on nearly practical used size (350 mm x $350 \mathrm{~mm}$ ) with cover concrete. These experiments have been done with considerably high lateral reinforcement contents of $7 \%$ to $10.5 \%$ under quasi-static loading rates. Also the longitudinal steel provided as four corner bars are on the high range of longitudinal reinforcement ratio $(11 \%-22 \%)$ based on confined core area. Three groups of laterally confined columns had been tested with three identically detailed columns in each group. Since one column in group A is stated to have failed prematurely rest of eight columns are considered for comparison.

Figure 3.3 indicates the strength gain of the considered eight specimens as compared to the model predictions. Here it should be noted that the data available is only the peak load of the column with the mention that at the attainment of peak load, only the core concrete had been present. Core peak strength of the columns were computed on this peak load and the core area.

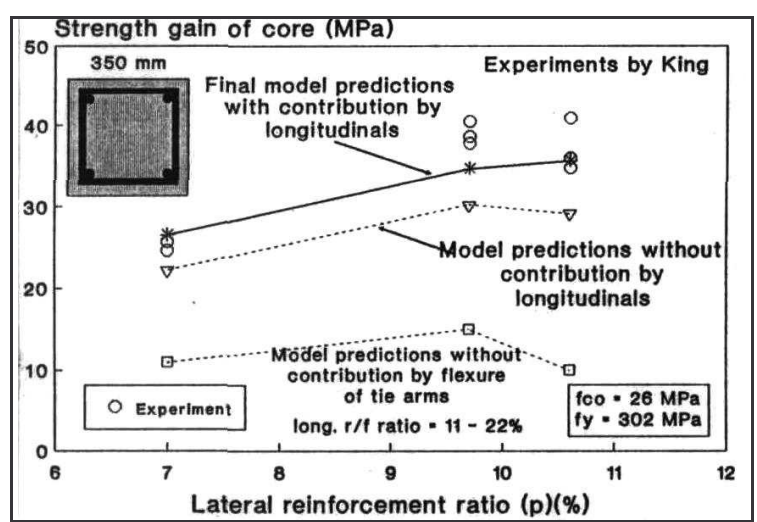

Fig. 3.3 Strength gain prediction (King) 
For identifying the significance of flexural stiffness of the tie arms, initial computations were carried out with flexural stiffness neglected. This was done by taking the flexure/shape factor, $F_{r}$ equal to unity (ie. $\varphi / L$ ratio is assumed zero). Under prediction of the gain is very clearly seen.

Secondly, for the purpose of clarifying the significance of the modification factor to account for the longitudinal reinforcement effect $\left(C^{*}\right)$, the model predictions were made without incorporating this factor, but with flexural effect of tie arms accounted. This was done by taking the factor $C^{*}$ equal to unity. Under this condition, the predictions are much improved, even though under prediction of the results are still seen.

Finally, the full Model is applied, by incorporating the modification factor $C^{*}$ on the uniformity factor. For this case the lateral spacing ratio of longitudinal reinforcement $(a / t)$ is equal to unity. In this event, only the effect of the amount of longitudinal reinforcement will influence the modification factor, $C^{*}$. Under this situation, the predictions are seen to become very close to the experimental observations.

Applicability of the model is further clarified by attempting predictions on practical sized columns with generally adopted reinforcement configurations.

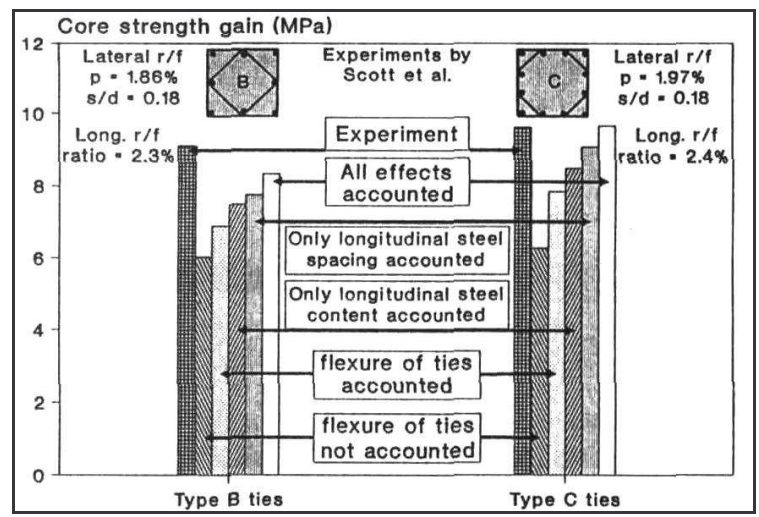

Fig. 3.4 Sensitivity of parameters in factor $\mathrm{C}^{*}$

A good set of data is available form the experimental research by Scott et al. [12]. Also as another very important criterion, they have explicitly evaluated the peak strength of the core concrete, in contrast to peak strength based on peak load and overall sectional area as reported by many researchers. These specimens consist of columns with eight and twelve longitudinal bar arrangements confined by tie configurations specified as type $B$ and type $C$. Two of the specimens, one each with type of ties have been tested under quasi-static loading rate of $3.3 \mu$ strains/sec. Two sets of type B and type C arrangements each consisting of four columns, had been tested under a high strain rate of 16700 $\mu$ strains/sec. Another set of type C columns with same detailing parameters as the other set but, with low yield strength for longitudinal reinforcement had been tested which is not taken for the comparison. Unconfined columns of same size had been tested under quasi-static as well as the higher dynamic strain rate which are used for the estimation of unconfined concrete strength in obtaining the respective strength gains under the different strain rates.

The columns tested with quasi-static loading were used to verify the modelling of the uniformity modification factor $\left(C^{*}\right)$ further, with the effect of amount of longitudinal reinforcement $(\rho)$ as well as their peripheral spacing ratio $(a / t)$, which will be less than unity in these cases. In Fig. 3.4, the refinements in predictions made by gradual application of factors are presented. The effect of flexural stiffness is accounted by using the relation proposed in Eq. 2.4. The bearing of $C^{*}$ is firstly shown with only the effect of longitudinal reinforcement ratio and secondly with only the effect of peripheral spacing of longitudinal reinforcement $(a / t)$. When both effects are simultaneously considered as proposed in Eq. 3.1, the predictions become quite close to observed. It is seen that the representation of the effect of longitudinal reinforcement in the uniformity relation is justified.

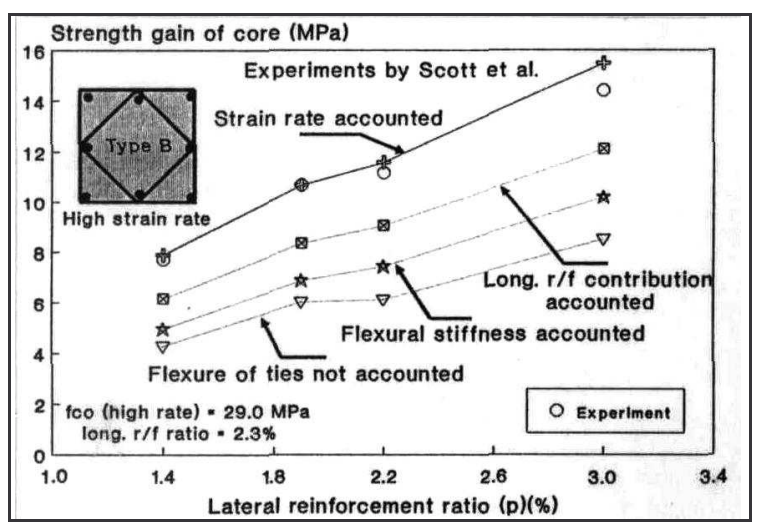

Fig. 3.5 Strength gain prediction (Scott type B)

The rest of the experimental series presented by Scott et al. have been conducted under high strain rates. Based on the argument at the 
beginning of this section on strain rate effect, the strength gain under high strain rates is represented by Eq. 3.4. The same multiplication factor as used for peak strength under high strain rates is used to obtain the strength gain under high strain rates.

$$
\left[\Delta f_{c}\right]_{\widetilde{\varepsilon}}=\Delta f_{c}(0.9+0.085 x \log \widetilde{\varepsilon})
$$

Therefore, the final prediction of strength gain under high strain rates for type $B$ and type $C$ columns are based on effects of longitudinal reinforcement and strain rate. The variation of predictive trend with the gradual incorporation of significant factors pertaining to confinement phenomenon is presented through fig. 3.5 for type $B$ and fig. 3.6 for type $C$ columns. In both cases when only truss action is assumed for lateral reinforcement, the predictions are markedly low. Incorporation of flexural contribution improves the prediction considerably. Further beneficial effects due to longitudinal reinforcement results in an even better prediction, which finally comes quite close to experimentally observed with the incorporation of the strain rate effect.

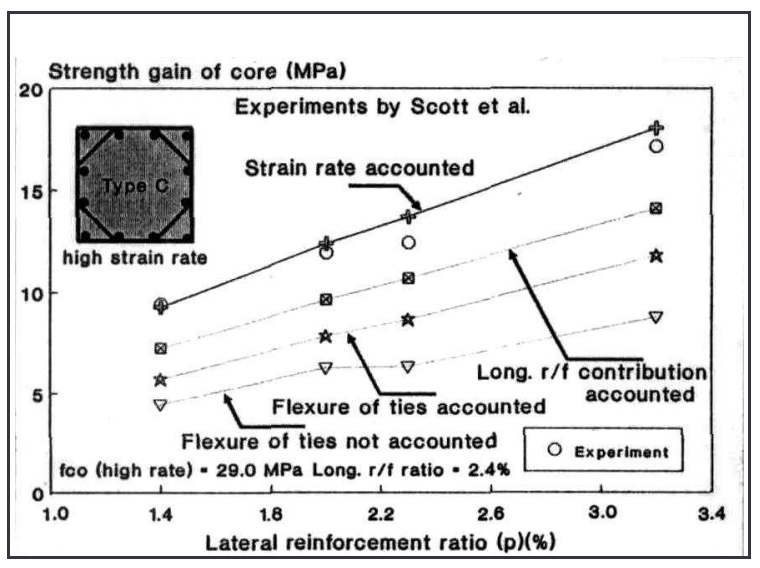

Fig. 3.6 Strength gain prediction (Scott type C)

\subsection{Application to Circular Sections with Longitudinal Reinforcement}

The developed Model is also applicable to circular sections as discussed in previous sections. In order to account for the higher lateral stress uniformity at a sectional level due to the circular lateral reinforcement, the flexure/shape factor, $F_{r}$, in the model is given a constant value of 15 , as its upper limit. To verify the model applicability in practical sized columns under axial loading, test results reported by Mander et al. [9], is utilized.
These columns are circular with a diameter of $500 \mathrm{~mm}$ and height of $1500 \mathrm{~mm}$. Longitudinal reinforcement are deformed bars numbering 8 to 24 in different columns. Lateral reinforcement are spirals, fabricated with plain round steel bar with yield strength varying from $307 \mathrm{MPa}$ to 340 $\mathrm{MPa}$. A cover of $25 \mathrm{~mm}$ had been provided for the spiral reinforcement. For a comprehensive comparison with the model, two experiments from pilot test and six experiments in the test series 1 , were selected. In the test series 2, the lateral reinforcement ratio and spacing had been kept constant while number of longitudinal reinforcing bars had been increased. In the final strength comparison, all test results are considered.

All specimens except one, in the test series have been tested under high strain rate of $13,000 \mu$ strains/sec simulating seismic conditions. One specimen was tested at a quasi-static loading rate of $3 \mu$ strains/sec. For each column tested, unconfined strength is explicitly specified in the literature.

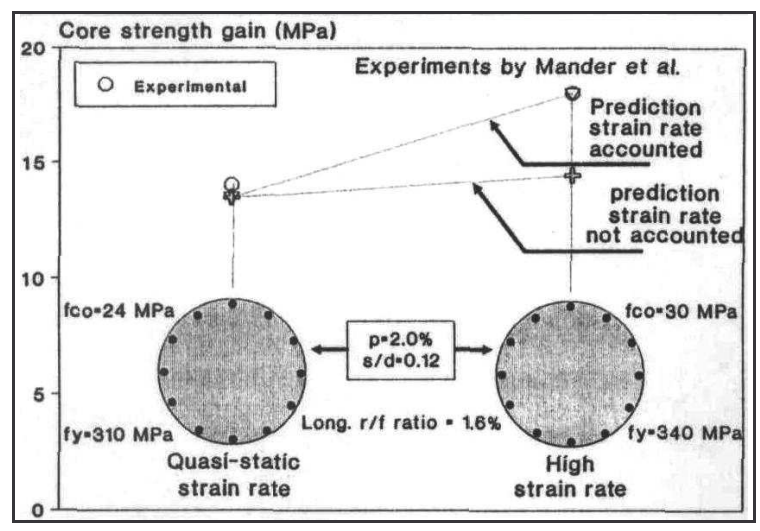

Fig. 3.7 Strength gain, Circular (Mander)

Effect to be identified in the beginning is the performance of the model under strain rate effect for circular columns. For this verification, two comparable tests conducted in the pilot test series were utilized. In these two specimens, the longitudinal and lateral reinforcement contents as well as detailing were identical. Only the straining rate is different. In the prediction of the circular cases, the modification factor for longitudinal reinforcement content and spacing $\left(C^{*}\right)$, is incorporated. It should be noted that due to the inherent uniformity at sectional level present in a circular column, the sensitivity of this factor on the strength gain is not very significant. 
The comparison of these two cases with model predictions, with and without consideration of strain rate effect is presented in fig. 3.7. It is seen from this figure that prediction is very good for low strain rate case. With incorporation of strain rate effect near perfect prediction is obtained for high strain rate cases too.

Since the strain rate effect is justified at this level, the Model with this effect incorporated is used for the prediction of six column specimens in the series, tested under high strain rates. The strength gain comparisons given in Fig. 3.8 shows quite good predictions by the Model.

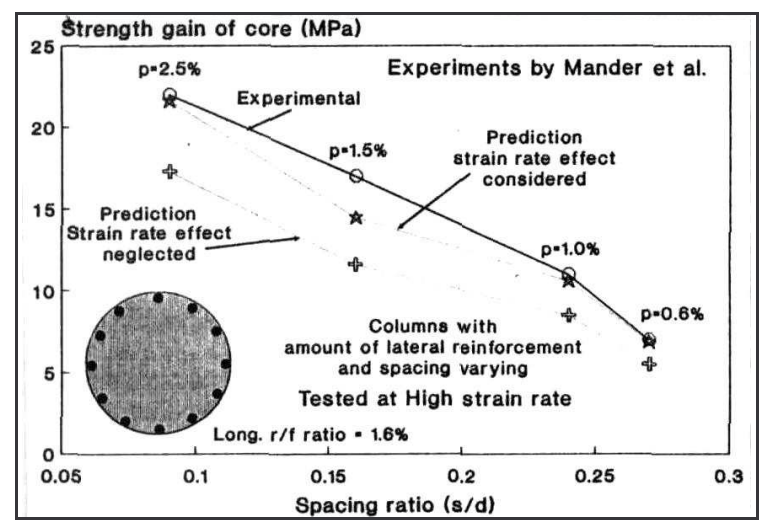

Fig. 3.8 Strength gain, circular (Mander gr.1)

Finally, the observed and Model predicted peak strengths for all experimental data discussed in this section are presented in Fig. 3.9, which indicates the versatility of the proposed Model.

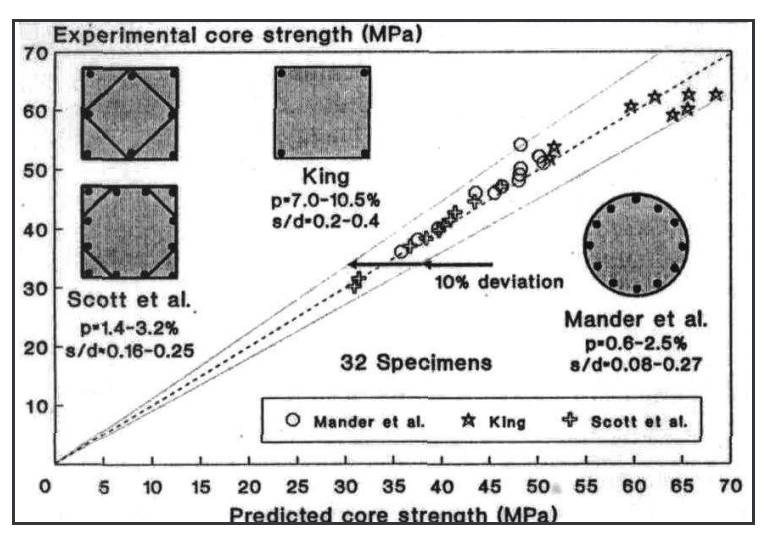

Fig. 3.9 Peak strength predictions

\section{Conclusions}

A previously developed "behaviour oriented macro-model" based on experimental investigations on idealized square concrete columns, and micro-mechanical FEM analysis results, for basic passive confined concrete cores, was the foundation for this paper. This paper presents an extension to this Model through rational stages for the prediction of strength gain in symmetric concrete cores confined by different geometric arrangements of lateral reinforcement.

In quantifying the confinement effectiveness three parameters which had been used in the derivation of the basic Model were redefined to account for the effects of complex lateral reinforcement layouts, supplemental confinement by longitudinal reinforcement, and rate of loading. These parameters were, "Limit uniformity factor $\left(K^{*}\right)$ ", "Uniformity factor $\left(K_{0}\right)$ " and lateral $\mathrm{r} / \mathrm{f}$ spacing ratio $(s / d)$. The flexure/shape factor $\left(F_{\mathrm{r}}\right)$ incorporated in the uniformity factors, which had been introduced to account for the contribution of flexure and shape of tie arms was further refined to address the better uniformity offered by complex geometrical arrangement of lateral reinforcement.

Spatial average confining stress, the identified major contributor in strength enhancement is evaluated based on confinement effectiveness index was evaluated in a rational way in the proposed Extended Model. The second effect of lateral stress uniformity in development of strength enhancement was similarly incorporated into the Extended Model based on conceptual minimum sectional average confining stress. This critical confining stress identified through FEM analysis was assumed at the weakest confined section, which would govern the strength of confined concrete. The unique relationship that was the developed for the prediction of strength enhancement, only dependent on the above minimum confining stress, was retained in the Extended Model too.

To account for the susceptibility of concrete strength to the effect of strain rate, a magnification factor was introduced to modify the strength of concrete in quasi-static loading conditions. Though steel yield strength in the range $300-350 \mathrm{MPa}$ was used for the experimental study which led to the basic Model, comparison of its predictions with experimental results of other researchers using other grades of steel indicates that yield strength of steel is not a significantly influential factor in confinement effectiveness.

The pooled comparison of experimental results by several researchers on practically used size 
confined columns with the Model indicates that the predictions are within a satisfactorily narrow band.

\section{Acknowledgement}

The author wishes to gratefully acknowledge the guidance and assistance rendered by Prof. K. Maekawa and Prof. H. Okamura of The University of Tokyo, during the experimental and FEM based analysis leading to this paper.

\section{References}

1. Brudette, E. G., and Hlisdorf, H. K., "Behavior of laterally reinforced concrete columns," Journal of the Structural Division, ASCE, Vol. 97, No. ST2, Feb. , 1971, pp. 587602.

2. Dilger, W. H., Koch, R., and Kowalczyk, R., "Ductility of Plain and Confined Concrete Under Different Strain Rates," ACI Journal, Vol. 81, No. 11, Jan.-Feb., 1984, pp. 73-82.

3. Fu, H. C., Erki, M. A., Seckin, M., "Review of Effects of Loading Rate on Concrete in Compression," Journal of Structural Eng., ASCE, Vol. 117, No. 12, Dec. 1991, pp. 36453659.

4. Fu, H. C., Erki, M. A., Seckin, M., "Review of Effects of Loading Rate on Reinforced Concrete," Journal of Structural Eng., ASCE, Vol. 117, No. 12, Dec., 1991, pp. 3660-3679.

5. King, J. W. H., "Further Notes on Reinforced Concrete Columns," The Structural Engineer, Nov., 1946, pp. 609-616.

6. Maekawa, K., Pimanmas, A., and Okamura, H., Nonlinear Mechanics of Reinforced Concrete, $1^{\text {st }}$ ed., Spon Press London, New York, 2003, p. 721 .

7. Maekawa, K., Takemura, J. Irawan, P., and Irie, M., "Continuum Fracture in Concrete Nonlinearity Under Triaxial Confinement," Proc. of JSCE, Vol. 18, No. 460, Feb., 1993, pp. 113-122.

8. Maekawa, K., Takemura, J. Irawan, P., and Irie, M., "Plasticity in Concrete Nonlinearity Under Triaxial Confinement," Proc. of JSCE, Vol. 18, No. 460, Feb., 1993, pp. 123-130.

9. Maekawa, K., Takemura, J. Irawan, P., and Irie, M., "Triaxial Elasto-Plastic and Fracture Model for Concrete," Proc. of JSCE, Vol. 18, No. 460, Feb., 1993, pp. 131-138.

10. Mander, J. B., Priestly, M. J. N., Park, R., "Observed Stress-Strain Behavior of Confined Concrete," Journal of Structural Eng., ASCE, Vol. 114, No. 8, Aug., 1988, pp. 1827-1849.
11. Pallewatta, T. M., Irawan, P., Maekawa, K., "Effectiveness of Laterally Arranged Reinforcement on the Confinement of Core Concrete," Journal of Materials, Concrete Structures and Pavements, JSCE, Vol. 28, No. 520, Aug. 1995, pp. 297 - 308.

12. Pallewatta, T. M., Irawan, P., Maekawa, K., "Verification of 3D Constitutive Model of Concrete in line with Capacity and Ductility of Laterally Reinforced Concrete Columns", Journal of Materials, Concrete Structures and Pavements, JSCE, Vol. 28, No. 520, Aug. 1995, pp. 309 - 321

13. Pallewatta, T. M., Irawan, P., Maekawa, K., "Confinement Effectiveness of Lateral Reinforcement Arrangements in Core Concrete", Concrete Library of The Japan Society of Civil Engineers, No. 27, Jun. 1996, pp. 221 - 247.

14. Pallewatta, T. M., "A Model for the Prediction of Strength Enhancement in Concrete Cores under Passive Lateral Confinement", Journal of the Institution of Engineers, Sri Lanka, Vol. XXXX, No. 01, Jan. 2007, pp. 17 - 27.

15. Scott, B. D., Park, R., and Priestley, M. J. N., "Stress-Strain Behavior of Concrete Confined by Overlapping Hoops at Low and High Strain Rates," ACI Journal, Vol. 79, no. 1, Jan.-Feb., 1982, pp. 13-27.

16. Somes, Norman F., "Compression tests on Hoop Reinforced Concrete," Proc., ASCE, Vol. 96, ST7, July, 1970, pp. 1495-1509.

17. Watstein, D., "Effect of Straining Rate on the Compressive Strength and Elastic Properties of Concrete," Journal of the ACI, Vol. 24, No. 8, Apr., 1953, pp. 729-744. 